\section{Estágio Supervisionado e saberes docentes: 0 diário reflexivo na formação inicial}

Supervised Internship and teaching knowledge: the education

Érica Danielle SILVA (UEM) erica_dsilv@yahoo.com.br

Neluana Leuz de Oliveira FERRAGINI (UNESPAR) neluanaferragini@gmail.com

Maria Izabel Rodrigues TOGNATO (UNESPAR) belinhatog@yahoo.com.br

Recebido em: 30 de maio de 2018. Aceito em: 13 de out. de 2018.

\title{
00000000000
}

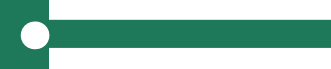


e implementadas no Estágio Supervisionado obrigatório quanto aos saberes docentes necessários ao seu desenvolvimento profissional, mobilizando, para isso, categorias elaboradas a partir dos diferentes saberes que norteiam a praxis docente. As análises nos mostram que o diário contribui para o processo reflexivo nesse contexto e pode conduzir os estudantes a uma formação docente crítica.

Palavras-chave: Estágio Supervisionado. Formação Reflexiva. Saberes Docentes.

Abstract: The Supervised Curricular Internship of the Language Course constitutes an important stage of the initial teacher education, in particular, to provide a moment of reflection on the teaching acting and of intersection between the diverse knowledge needed for this formation, such as the knowledge to be taught (content to be taught and learned) and the knowledge for teaching (didactic-pedagogical aspects and methodological dimension) (HOFSTETTER, SCHNEUWLY, 2009, LIBANEO, 2015). In this research, we assume the Supervised Internship as a context for discussing the reflective teacher education, based on different theoretical contributions derived from Schön (1983, 1987, 1988), Zeichner (1994), Pimenta (2012), Bronckart (2009a), Bota et al. (2006) and Stutz (2012). Considering the reflective diary as a fundamental instrument for the reflective process, which allows us to (re)signify the teaching acting, as a corpus of analysis, we resort to the diaries produced by two students of the last year of the Language Course, with qualification in Portuguese language. Under this bias, our objective is to understand the reflection process of the teacher in his or her education development from the recordings of the classes observed and implemented in the mandatory Supervised Internship regarding the teaching knowledge necessary to his or her professional development. The analyzes show that the diary contributes to the reflective process in this context and can conduct the students to a critical teacher education.

Keywords: Supervised Internship. Reflective teacher education. Teaching knowledge.

\section{Introdução}

No campo da Linguística Aplicada, as pesquisas no contexto de formação inicial de professores de línguas desenvolvidas nos últimos anos têm-nos mostrado a importância do exercício da reflexão acerca do trabalho docente pelas práticas formativas (REICHMANN, 2013; DIAS, 2013; FREITAS; MEDRADO, 2013; PEREZ, 2013). Nesse contexto, as tarefas de registro de observações de aulas e de regência no Estágio Supervisionado dos cursos de Letras, por meio de relato, diários e reflexão de aulas têm um papel fundamental para o desenvolvimento do futuro professor.

Para este estudo, recorremos aos diários reflexivos sobre aulas observadas e implementadas de licenciandos do último ano do curso de Letras, habilitação Português, de uma universidade pública do interior do Estado do Paraná. A opção por diários reflexivos justifica-se pela possibilidade de promover uma oportunidade de maior engajamento do professor em formação em relação à constituição do trabalho docente 
V. 8 (3)

204-229

out-dez

2018

e a muitas questões indispensáveis à realidade educacional, visando ao desenvolvimento de sua capacidade crítica quanto ao uso da(s) linguagem(ns), bem como da sua tomada de consciência acerca de seu papel social no exercício de sua profissão. Por essas razões, propomos uma discussão acerca do desenvolvimento da capacidade reflexiva dos licenciandos por meio de diários, no sentido de estabelecer possíveis relações entre os saberes docentes e o papel do Estágio Supervisionado.

Esse trabalho pode propiciar aos futuros professores a oportunidade de estabelecer relações entre os saberes e capacidades docentes necessários ao seu crescimento profissional (HOFSTETTER; SCHNEUWLY, 2009; STUTZ, 2012), avaliando de modo sistemático tanto a práxis docente do trabalho observado quanto a própria atuação em sala. Com isso, buscamos entender o processo de reflexão crítica do professor em formação inicial a partir dos registros das aulas observadas e implementadas no Estágio Supervisionado envolvendo os saberes docentes necessários à sua profissionalização. Para tanto, pautamos nossos estudos nos aportes teórico-metodológicos do dialogismo de Bakhtin/Volochinov (2003) e da perspectiva da reflexão crítica para a formação de professores (SCHÖN, 1983, 1987, 1988; ZEICHNNER, 1994, 2010; GIMENEZ, 1994, 1995, 1999; PIMENTA, 2012), bem como nas críticas à falta de métodos e técnicas específicas de "'reflexivização' para a formação de profissionais" (BOTA et al 2006, p.89). Além disso, tomando por base os estudos de Stutz (2012, p.89) e de Bronckart (2009a), consideramos relevante discutirmos o papel da reflexividade para o desenvolvimento da inteligibilidade e da tomada de consciência na formação de profissionais, uma vez que a reflexão pode contribuir para sugestionar a compreensibilidade da práxis docente (BOTA et al 2006, p. 93). Assim, a fim de propiciar um debate social, apontamos alguns questionamentos como elementos norteadores de nossa proposta de discussão:

1. Quais saberes docentes são mobilizados e articulados nos diários produzidos pelos professores em formação participantes de nossa pesquisa?

2. Em que aspectos o Estágio (observação e regência) contribui para a reflexão do trabalho docente e seus elementos constitutivos na formação inicial de professores de língua portuguesa? 
A partir do exposto, sistematizamos este estudo em três momentos. Primeiramente, tecemos a fundamentação teórica acerca da formação e da profissão docente como prática reflexiva, sobretudo, no que concerne à produção de saberes e ao desenvolvimento de capacidades docentes. Em seguida, abordamos os diários reflexivos como estratégia metodológica do componente de Estágio Supervisionado que permitem ao professor em formação protagonizar análise da práxis docente, construindo um repertório formativo e profissional que transcende ao conhecimento teórico-técnico. Na sequência, desenvolvemos as discussões sobre os dados e, por fim, tecemos nossas considerações finais.

\section{A formação inicial do professor reflexivo}

A prática reflexiva, enquanto orientação para a formação de professores de línguas, é uma tendência que foi desenvolvida com expressivo fôlego a partir da década de 1990, no Brasil. Nesse período, reivindicou-se com maior empenho um modelo de formação que superasse os princípios da racionalidade técnica até então vigentes, segundo os quais os professores deveriam solucionar problemas e alcançar resultados esperados a partir da reprodução de teorias propostas por especialistas/estudiosos. Os saberes do professor eram compreendidos, nessa perspectiva, como habilidades adquiridas por imitação de modelos ou pelo domínio de técnicas precisas, desconsiderando-se as experiências de vida, a história profissional, as relações professoraluno-escola-sociedade, entre outros. A concepção reflexiva advogada passa a conferir ao professor, em seu trabalho em contexto real de sala de aula, um status de protagonista e de agente, o que significa, segundo Zeichner (2008, p. 539), que professores exercem "um papel ativo na formulação dos propósitos e finalidades de seu trabalho e de que devem assumir funções de liderança nas reformas escolares". O processo reflexivo implica, pois, em sua essência, a produção de conhecimento pelo professor, e, consequentemente, de metodologias de ensino mais eficazes e apropriadas de acordo com o contexto de atuação.

Nessa perspectiva, Schön $(1983,1987,1988)$ deriva o conceito de "reflexão-na-ação" (reflection-in-action), explicando que as pesquisas desenvolvidas pela abordagem reflexiva podem ser realizadas no momento da ação (reflection-in-action) ou após uma aula implementada (reflection-on-action) a fim de se fazer uma análise posterior. Isso 
V. 8 (3)

204-229

out-dez

2018

posto, o conceito de professor reflexivo ultrapassa o valor semântico do adjetivo que qualifica o profissional, uma vez que o movimento da reflexão vai além do ato de refletir; compreendendo a "construção de conhecimento, através da reflexão, análise e problematização desta, e o reconhecimento do conhecimento tácito, presente nas soluções que os profissionais encontram em ato" (PIMENTA, 2006, p. 20).

Zeichner (1994) defende que a reflexão pode ser técnica, prática e crítica. Tognato (2002) explica que, para o autor, a primeira diz respeito à valência dos meios empregados no intuito de alcançar os objetivos; a segunda envolve explicação e esclarecimento das conjecturas que subjazem a prática docente, por meio de "questionamentos tais como, o que leva o professor a desenvolver o que desenvolve ou os alunos a aprenderem o que aprendem, se o que está fazendo em sala de aula leva os alunos a aprenderem" (TOGNATO, 2002, p.37); e a terceira constitui-se de critérios éticos e morais ao se fazerem questionamentos críticos no sentido de se explicitar as razões das ações. Quanto a esse terceiro tipo de reflexão, Arruda e Gimenez (2004, p.32) destacam que o professor que "reflete criticamente avalia o contexto em que a escola e os alunos estão envolvidos, unindo suas questões morais e éticas para esclarecer as ações e promover mudanças que vão além da sala de aula".

Segundo Libâneo (2012), não obstante Schön (1983, 1987) assuma uma posição pragmática e Zeichner (1994) eleja um posicionamento pragmático-reconstrucionista, ambos pesquisadores são contrários à perspectiva técnica. Nesse sentindo, Libâneo (2012, p.77), em nota de rodapé, explica que, para Schön, a "reflexão é um processo ligado intrinsecamente à experiência, de modo que o conhecimento prático é um processo de reflexão na ação [...]", enquanto Zeichner assume a reflexão na prática voltada para a reconstrução social, por isso a considera uma atividade crítica.

Postuladas algumas concepções sobre reflexão na prática docente, pontuamos que essa perspectiva também recebe críticas, dentre elas, apontamos, laconicamente, a visão de Pimenta (2012), para quem a forma como o conceito de professor reflexivo tem sido apropriado em território brasileiro reside muito mais em expressão de uma moda:

à medida que o despe de sua potencial dimensão políticoepistemológica, que se traduziria em medidas para a efetiva elevação do estatuto da profissionalidade docente e para a melhoria das condições escolares [...] (PIMENTA, 2012, p. 53).

Ademais, Facci (2004, p. 52) explicita que "a reflexão crítica 
leva o professor a questionar a realidade e buscar uma sociedade mais justa e humana, e o professor tem que estar ciente da sua responsabilidade social". A perspectiva de Zeichner refere-se aos seguintes aspectos: a uma atenção tanto sobre a própria prática quanto sobre os estudantes e as condições sociais em que essa prática se insere; ao "impulso democrático e emancipador", considerando-se as "dimensões sociais e políticas do ensino", dentre outras; e à reflexão "mais como uma prática social do que apenas como uma atividade privada". Segundo Facci (2004, p. 53), "enquanto Schön trata de um professor práticoreflexivo, Zeichner entende o professor como investigador". A autora ainda destaca que, no campo da pesquisa acadêmica, Zeichner (1998) salienta a necessidade de maior interação entre os discursos do docente e do discente, logo, é abordagem crítica por fazer referência à reflexão coletiva e envolver a dimensão política. No entanto, Facci (2004, p. 54) enfatiza que a dimensão política de tal pesquisador pode enveredarse aos pressupostos burgueses mostrando "um humanismo possível dentro do capitalismo", o que para a autora é um "grande engodo". Facci (2004) finaliza a discussão explicitando que:

refletir coletivamente não significa que esta reflexão esteja
pautada em argumentos que levem em consideração o contexto
sócio-histórico no qual o professor desenvolve sua prática,
ou mesmo que se analisem as relações que perpassam os
pesquisadores e os professores. Não é suficiente apenas dar 'voz
aos pesquisadores e professores', é preciso que eles reflitam
em que condições econômicas, políticas e sociais desenvolvem
a profissão e que necessidades postas pelo capital exigem dos
professores esta ou aquela postura (FACCI, 2004, p. 54).

Corroboramos com Pimenta (2006; 2012) e Facci (2004) quanto ao fato de que devemos considerar a dimensão política ao tratar de formação de professores e do desenvolvimento da capacidade reflexiva. Sob tal enfoque, os saberes docentes já não consistem nas capacidades adquiridas por imitação de modelos ou pelo domínio de técnicas. Ao discutirmos o posicionamento pragmático-reconstrucionista de Zeichner, consideramos as características do professor crítico-reflexivo descritas por Pimenta (2012, p. 75), que compreendem as seguintes ações: a) fazer e pensar a relação entre teoria e prática; b) assumir o papel de agente preocupado com a apreensão das contradições; c) ter atitudes e ações críticas frente ao mundo e sua atuação; d) desenvolver uma apreensão teórico-prática do real; e, e) refletir de modo sociocrítico e emancipatório. 
v. 8 (3)

204-229

out-dez 2018

Ao destacar o protagonismo do sujeito professor, Pimenta (1998) defende que a licenciatura deve desenvolver nos alunos:

conhecimentos e habilidades, atitudes e valores que lhes possibilitem permanentemente construir seus saberes-fazeres docentes com base nas necessidades e nos desafios que 0 ensino como prática social lhes coloca no cotidiano (PIMENTA, 1998, p. 163-164).

A reflexividade é um importante eixo norteador de formação que encontra no Estágio Supervisionado condições propícias para sua prática. Para Pimenta e Lima (2012, p. 55), cabe ao Estágio oferecer:

atividades que possibilitem o conhecimento, a análise, a reflexão do trabalho docente, das ações docentes, nas instituições, a fim de compreendê-las em sua historicidade, identificar seus resultados, os impasses que apresenta, as dificuldades (PIMENTA; LIMA, 2012, p. 55).

De acordo com as autoras, tal conhecimento compreende o estudo, a análise, a problematização, a reflexão e proposição de soluções para o processo de ensino e aprendizagem, bem como a produção, a implementação e a avaliação de projetos de ensino tanto para as salas de aula como para outros espaços escolares, além do uso de técnicas, métodos e estratégias de ensinar em diversificadas situações, o trabalho com a leitura e o reconhecimento de diferentes teorias que podem constituir as práticas pedagógicas.

Nessa perspectiva, buscamos oferecer oportunidades para que o professor em formação inicial possa examinar criticamente suas experiências, suas práticas e (re)construir sua identidade, assumindo um compromisso com sua profissão de modo consciente e atento às especificidades dos locais de trabalho. Entendemos que, para isso, as estratégias pedagógicas devem ser diversificadas e construídas a partir de relações interinstitucionais e interpessoais. Um dos instrumentos pedagógicos possíveis para esse trabalho é o diário reflexivo, que, dadas as suas condições discursivas, potencializa o registro de sentimentos e reações, em espaço de investigação e de entendimento de procedimentos de ensino-aprendizagem e do contexto de atuação. É sobre o Diário como gênero utilizado para a reflexão crítica e para uma compreensão mais ampliada sobre o trabalho docente e o contexto educacional em que ele se insere que discutiremos na próxima sessão.

Os diários reflexivos na formação inicial de professores de língua 


\section{portuguesa}

A escrita reflexiva é uma ferramenta que permite o estudo de representações e/ou percepções sobre o trabalho docente, promovendo a reflexão e o desenvolvimento do professor (PEREZ, 2013). Trata-se de uma oportunidade ao professor em formação de analisar os aspectos constitutivos do trabalho docente no qual atuará futuramente com vistas a um preparo mais seguro e preciso acerca das questões de ensino e de aprendizagem, assim como sobre a prática profissional docente ou a situação de trabalho em um sentido mais amplo. Nessa perspectiva, Dias (2013) defende o trabalho de formação docente por meio de diários reflexivos por propiciarem uma redefinição das experiências vividas, reconstruindo novos sentidos para sua história. Para Dias (2013, p.68), tais diários funcionam como "um espaço de (trans)formação profissional" com exemplos reais que representam, ressignificam e podem reorganizar a práxis docente, contribindo para o letramento docente.

Por meio dessa estratégia pedagógica, a prática reflexiva pode contribuir para a tomada de consciência sobre o agir docente e os elementos que os constituem, o que pode resultar na inteligibilidade e no desenvolvimento do profissional. Fundamentando-se em Zeichner (2008), Stutz (2012) destaca a reflexão como uma possibilidade de reconstrução da experiência por meio da interação social com o intuito de que um dado grupo ou comunidade possa crescer em conjunto. Stutz (2012, p. 90), fundamentando-se em Bronckart, explicita que:

a reflexividade transita pelo pensamento verbal, pela expressão em palavras para redimensionar essa experiência. Ou seja, as experiências quando ressignificadas em atividades contribuem para a formação da consciência. A tomada de consciência é condição para aumentar a inteligibilidade mas ela só se torna profícua ao gerar uma reorganização das significações da ação, que por sua vez reintegra as diversas variantes da ação e possibilita a construção de uma concepção pessoal da ação (BRONCKART, 2009b). Compreendemos a tomada de consciência como a capacidade que o indivíduo utiliza para acessar ou para fazer contato social com o próprio pensamento para agir sobre ele, para criar representações sobre o mundo, sobre a relação dialética entre o indivíduo e o mundo, e sobre si mesmo (BRONCKART, 1999). A consciência do indivíduo sobre um objeto ou experiência apresenta lacunas porque a realidade não pode ser percebida pela pessoa como uma imagem refletida em um espelho. Fruto da formação sócio-histírica da pessoa, a consciência fornece retratos parciais dos objetos, experiências e das relações interpessoais. (STUTZ, 2012, p. 90). 
V. 8 (3)

204-229

out-dez

2018

A experiência docente, por conseguinte, pode encontrar na prática reflexiva um caminho para (res)significar a praxis, contribuindo para a contrução de um sujeito mais crítico e consciente de sua própria atuação social. Dentreospossíveiscaminhosparaaautoreflexão, destamos o diário reflexivo, o qual, de acordo com Freitas e Medrado (2013, p. 92) também pode colaborar com a construção da identidade profissional docente, uma vez que a produção de textos de caráter reflexivo pode estimular a articulação e legitimação de identidades autorreferenciadas. Ainda segundo Freitas e Medrado (2013, p. 93), no sentido vygotskiano, tal atividade interna é "o próprio processo de reflexão crítica". Por isso, as autoras consideram que o diário reflexivo, utilizado em contextos de formação inicial ou continuada, visa à ampliação da reflexão crítica. Corroborando com as autoras, Reichmann (2007, p. 229) explica que, ao utilizar o diário reflexivo, "[...] o professor/aprendiz/autor pode colocar suas dúvidas, anseios, percepções, questões, críticas, conflitos - enfim, documentar suas tensões, reflexões e (re) elaborar crenças e práticas".

Nessa perspectiva, Perez (2013) enfatiza que os professores em formação, na prática de escrita e análise dos próprios textos, a partir de contextos singulares, podem (res)significar a práxis docente, e ainda ressalta:

esses textos materializam e, assim, dão acesso a representações/ interpretações construídas e validadas socialmente sobre o trabalho docente para que sejam conhecidas, discutidas, transformadas e/ou cristalizadas (PEREZ, 2013, p.116).

Enfim, o processo reflexivo pelo uso de diários na formação inicial permite a construção da reflexão sobre a prática docente reconfigurando-a e ressignificando-a a partir de descrições, análises e questionamentos que podem ser fundamentais para uma preparação mais precisa e segura com vistas a uma atuação profissional mais consciente e autônoma.

\section{O Estágio Supervisionado e o processo de formação: o que revelam os diários reflexivos}

No quarto ano do curso, os professores em formação inicial realizam 20 (vinte) horas de observação nas turmas de Ensino Médio de escolas públicas (15h) e privadas (5h) e mais 20 (vinte) horas de regência no contexto público. A regência ocorre no formato de Oficinas de Linguagem, no contraturno, com conteúdos de revisão e de preparação 
voltados para processos seletivos, em especial, de Universidades do próprio município ou da região, compreendendo, assim, os seguintes eixos de ensino de Língua Portuguesa: a) Leitura e Análise Linguística; b) Literatura; e c) Produção de Textos. Os estagiários, sempre que possível, podem escolher em qual dos eixos gostariam de realizar a regência, atuando em duplas ou trios ${ }^{1}$, e são os responsáveis, sob orientação, pela eleição dos conteúdos a serem ministrados, desde que estejam em consonância com o nível de ensino. As Oficinas são organizadas respeitando-se o calendário da instituição e as demais atividades desenvolvidas no contraturno e são abertas aos alunos de todas as séries do ensino médio. Cada encontro da Oficina tem duração de 4 (quatro) horas, podendo realizar-se de uma a três vezes por semana. Desse modo, as Oficinas somam um total de 60 (sessenta) horas em cada colégio, visto que os três eixos são desenvolvidos.

Para os diários das etapas de observação ${ }^{2}$ e de regência, os professores em formação seguem um roteiro que, tomando por base a proposta tal como é explicada por Liberali (1999), contempla os seguintes passos: a) Descrever (o que eu faço ou o outro faz? Relato concreto dos eventos vivenciados em sala de aula); b) Informar (o que isso significa? Evidenciar quais os princípios e teorias envolvidos no processo de ensinar e aprender que subjazem às ações do professor); c) Confrontar (Como me tornei assim? Quero ser assim? Relacionar ações e fatores culturais, políticos, econômicos, que ultrapassarem a sala de aula); e, d) Reconstruir (Como agir de forma diferente? Confrontar nossas visões e práticas, compreendendo sua relevância e consistência com valores morais e éticos, definindo a reconstrução de nossas ações).

O corpus de nossa pesquisa consiste nos diários reflexivos produzidos por duas professoras em formação inicial 3 sobre as aulas observadas em contexto privado e público no ano letivo de 2017. Para a análise de tais dados, elaboramos as seguintes categorias de análise e respectivos critérios a partir dos diferentes saberes que norteiam a práxis docente, conforme ilustra o Quadro 1.

\footnotetext{
${ }^{1}$ A preferência é que o Estágio aconteça sempre em duplas, mas, por vezes, torna-se necessária a formação de trios.

${ }^{2}$ Os licenciandos, durante as observações, anotam a rotina da sala de aula e a práxis do professor observado. Alguns docentes solicitam esse material, o qual é repassado pelos estagiários. Contudo, na maioria das vezes, não há retorno aos professores da rede básica.

3 Ressaltamos que os alunos participantes foram previamente informados da pesquisa e assinaram o Termo de Consentimento Livre e Esclarecido.
} 
v. 8 (3)

204-229

out-dez

2018

Quadro 1 - Categorias e critérios de análise

\begin{tabular}{|c|c|c|}
\hline SABERES & CATEGORIAS & CRITÉRIOS \\
\hline \multirow{3}{*}{$\begin{array}{l}\text { Saberes provenientes } \\
\text { da formação }\end{array}$} & Saberes teóricos & $\begin{array}{l}\text { Saberes teóricos } \\
\text { apontados na construção } \\
\text { dos discursos do professor } \\
\text { em formação como forma } \\
\text { de validar seu } \\
\text { posicionamento. }\end{array}$ \\
\hline & $\begin{array}{l}\text { Saberes } \\
\text { metodológicos }\end{array}$ & $\begin{array}{l}\text { Saberes metodológicos } \\
\text { apontados, discutidos e } \\
\text { analisados ao longo do } \\
\text { diário. }\end{array}$ \\
\hline & $\begin{array}{l}\text { Relação teoria e } \\
\text { prática }\end{array}$ & $\begin{array}{l}\text { Saberes teórico-práticos } \\
\text { relacionados pelo professor } \\
\text { em formação inicial. }\end{array}$ \\
\hline \multirow[t]{2}{*}{ Saberes pessoais } & $\begin{array}{l}\text { Conhecimentos e } \\
\text { experiências } \\
\text { pessoais, } \\
\text { provenientes da } \\
\text { própria experiência } \\
\text { na sala de aula e } \\
\text { na escola }\end{array}$ & $\begin{array}{l}\text { Conhecimentos e } \\
\text { experiências pessoais são } \\
\text { retomados como exemplos } \\
\text { de modo a contribuir para } \\
\text { um posicionamento crítico } \\
\text { e reflexivo. }\end{array}$ \\
\hline & $\begin{array}{l}\text { Conhecimentos } \\
\text { culturais, } \\
\text { familiares, de } \\
\text { convívio pessoal }\end{array}$ & $\begin{array}{l}\text { Correlação com os s } \\
\text { culturais e sociais. } \\
\text { Contribuiç̃̃es dessas } \\
\text { informaç̃̃es para a } \\
\text { construção reflexiva do } \\
\text { professor em formação. }\end{array}$ \\
\hline \multirow{3}{*}{$\begin{array}{l}\text { Saberes provenientes } \\
\text { da formação e das } \\
\text { experiências pessoais } \\
\text { - modos de } \\
\text { identificação e reflexão } \\
\text { docente }\end{array}$} & $\begin{array}{l}\text { O professor pelo } \\
\text { olhar do próprio } \\
\text { licenciando }\end{array}$ & $\begin{array}{l}\text { Imagem que o professor } \\
\text { em formação produz do } \\
\text { professor observado, da } \\
\text { situação de sala de aula } \\
\text { em que esteve inserido e } \\
\text { de suas própria atuação. }\end{array}$ \\
\hline & $\begin{array}{l}\text { Atitudes e ações } \\
\text { criticas do } \\
\text { professor em } \\
\text { formação }\end{array}$ & $\begin{array}{l}\text { Atitude valorativa do } \\
\text { professor em formação } \\
\text { diante do estágio. }\end{array}$ \\
\hline & $\begin{array}{l}\text { Reflexividade sócio- } \\
\text { crítica e } \\
\text { emancipatória }\end{array}$ & $\begin{array}{l}\text { Avaliação e autoavaliação } \\
\text { crítica quanto aos } \\
\text { conhecimentos adquiridos. } \\
\text { Reconstrução crítica da } \\
\text { aula observada/ministrada. }\end{array}$ \\
\hline
\end{tabular}

Fonte: As autoras.

As categorias acima evidenciam saberes provenientes da formação acadêmica e saberes oriundos das experiências pessoais (os quais têm como fontes de aquisição a família, o ambiente, a educação, as experiências com a escola, com professores, como aluno, entre 
outros). Alguns desses saberes já são instituídos e internalizados, outros que estão se constituindo materializam-se com maior evidência nos processos de reflexão, o que nos permite constatar a relevância de um trabalho mais sistematizado com a reflexividade na formação inicial. A partir dessa orientação metodológica, direcionamos nosso olhar para os diários ${ }^{4}$ elaborados sobre o período da observação e da regência, em seções específicas.

Os diários reflexivos sobre aulas observadas: a atuação do outro

Na prática de observação de aulas, há uma regularidade nos apontamentos da Professora em Formação Inicial 1 (PFI1) sobre a imagem construída acerca das ações do professor regente. Das dez aulas que compõem o diário reflexivo do período de observação, em cinco, PFI1 enuncia que o professor é "o detentor do saber". Essa imagem é justificada por duas condições: (a) o professor é aquele que apenas transmite o que deve ser adquirido pelo aluno que é, por sua vez, passivo neste processo; e (b) o professor apresenta propriedade e autonomia durante as correções e explicações. Entendemos que PFI1 destaca a autonomia do professor referindo-se ao seu vasto conhecimento, sobretudo, estrutural da língua e ao seu preparo para transmitir o conteúdo com segurança.

A Professora em Formação Inicial 2 (PFI2), embora não explicite a ideia do professor como "detentor de conhecimento", demonstra que compartilha dessa visão, o que podemos pressupor a partir da descrição da aula 19 (Excerto 1).

Excerto 1 - Descrição de aula de PFI2

A professora inicia a aula perguntando se algum aluno tem alguma dúvida referente a aula passada (regionalismos 30). A professora [...] divide o quadro em três partes e explica detalhadamente o periodo, faz como se fosse um fichamento coloca a época, autor, fator histórico da época explica as características e o contexto histórico [...] Ao final da explicação ela pede que os alunos abram a apostila [...] para fazerem as questões da página 6 à 13 .

${ }^{4}$ As informações contidas nos diários foram transcritas de acordo com o original, assim, não foram corrigidos aspectos ortográficos ou sintáticos. 
V. 8 (3)

204-229 out-dez 2018

Os dados acima revelam que a aula não é uma construção coletiva, restringindo-se ao repasse de informações e à solicitação de atividades. Destarte, ao compararmos a visão das duas PFI sobre o mesmo professor descrito, constatamos uma concepção de professor ora como responsável pela transmissão dos conhecimentos, ora como aquele que controla temporalmente as atividades, o que Geraldi (2015) denomina de "professor controlador do tempo".

A concepção de professor como responsável pela transmissão do conhecimento pode estar atrelada tanto aos saberes teóricos oriundos da formação acadêmica, como dos saberes pessoais, já que culturalmente ainda se mantém a concepção de professor como "detentor de conhecimento". Isso porque se construiu historicamente um discurso institucional escolar que funciona pela instalação de discursos autorizados pela ciência, promovendo o apagamento dos confrontos dos sentidos produzidos e das relações de poder que perpassam esses sentidos. Dessa forma, o professor, enquanto representante da ciência, do saber e da verdade, é o responsável por garantir a reprodução dos saberes legitimados e das práticas linguísticas normativas.

Em uma das aulas observadas no contexto privado de ensino, PFI1 explicita que o papel de detentor do saber também pode ser atribuído ao livro didático, afirmando que o professor pode usar:

as respostas sem o auxílio do livro, porém, como é de característica da educação particular o cumprimento do material apostilado, a professora utiliza dando continuação com a paginação das atividades (Aulas 6 e 7, p. 28).

Em outro momento, tal instrumento aparece como responsável pelos saberes escolares: "metodologia marcada pela presença do livro didático como detentor do conhecimento, dado que ela seguiu a disposição metodológica e de conteúdo da ferramenta didática" (Aula 3, p. 24). A respeito do livro didático nas aulas observadas em instituição pública PFI2, salienta que a "[...] utilização sistemática do livro didático, que deveria ser um apoio [...] torna-se o detentor do saber já que a professora faz a leitura dele como referência ao conteúdo [...]" (p. 50). Isso nos possibilita ver algumas possíveis implicações acerca do papel do livro didático, que pode limitar, de algum modo, tanto o trabalho do professor em relação à sua autonomia sobre o ato de ensino quanto ao processo de aprendizagem dos alunos. 
Observar diferentes contextos é fundamental para o período de formação inicial, pois permite ao professor em formação perceber a resistência de concepções tradicionais de ensino e aprendizagem de Língua Portuguesa, na qual o professor e o livro didático são legitimados como a referências máximas do saber. Por um lado, a posição de autonomia é sustentada pela necessidade de se impor frente à precariedade de condições, quando considerada a maioria dos contextos públicos $\mathbf{x}$ salas lotadas, falta de material apropriado, falta de respeito pelo professor $\mathbf{x}$ e, por outro lado, as práticas de cerceamento orientam também o contexto privado, já que se concentram no fator quantitativo, perpetuando, desse modo, uma prática de ensino-aprendizagem de língua deslocada do uso, da reflexão.

Nesse contexto, como o professor em formação inicial sugere a reconstrução de aulas observadas em que o docente é o detentor do saber ou se limita às informações do livro didático? Para essa discussão, selecionamos a reconstrução de uma aula de PFI2, em que, ao confrontála, pontua que o professor se debruçou no livro didático para abordar a obra A Moreninha, conforme segue (Excerto 2).

Excerto 2 - Reconstrução de aula de PFI2

A partir da aula tradicionalista apresentada, a aula poderia ser organizada de uma forma mais atrativa. Iniciando a aula apresentando a capa do livro a moreninha e juntamente comos alunos fazer o levantamento de hipóteses $a$ partir das informaçס̃es da capa, pedir que eles tentem supor o que se passa na história, mostrar data e leva-los a entender o contexto histórico da época, questionar se isso interfere na história, deixar que os alunos coloquem suas sugestões e hipótese diante da capa.

Após fazer a leitura da sinopse do livro que vem na capa do livro, sem contar o final, continuar o dialogo buscando ver se eles conseguem fazer inferências diante da sinopse, levar uma foto da época que foi escrito, uma foto do autor, contarumpouco sobre ele e assim ler um fragmento da obra no livro original, talvez a mesma que o livro didático ou outra que juga-se pertinente.

Apresentar o gênero colocando suas caracteristicas, falas sobre o vocabulário, questionar se fosse escrito nos dias de hoje seria da mesma forma? Após todas as etapas de pré-leitura, leitura e pós- leitura, apresentar que existem vários tipos de romance falar sobre os autores romancistas e talvez sugerir uma atividade de leitura, pedindo que os alunos busquem texto de escritores romancistas dessa época e trouxessem para lermos e interpretarmos em uma aula seguinte. Contudo não posso deixar de elogiar a professora, pois não sabemos como fora sua formação e quais são seus medos e dificuldades e decepções diante da sala de aula, por isso creio que ela tenha feito o melhor que ela pode. (grifos nossos) 
V. 8 (3)

204-229 out-dez 2018

Ao propor um encaminhamento que transcenda a apresentação do livro A Moreninha feita pelo livro didático adotado pela escola, observamos a capacidade de articular os saberes de formação a partir de uma descrição da aula, indicando-nos a importância de avaliarmos o processo de ensino e aprendizagem e não a pessoa do professor, o que comumente ocorre neste período de formação inicial. Na reconstrução sugerida, há um relato de identificação de PFI2 sobre práticas e saberes oriundos da formação docente inicial que podem, possivelmente, organizar suas práticas futuras. O encaminhamento sugerido articula consciente e coerentemente concepções teórico-metodológicas de leitura, da teoria de gêneros e das dimensões sociais dos enunciados, conforme destacamos no trecho do diário reproduzido acima. Com isso, consideramos que houve a reflexividade sócio-crítica e emancipatória, visto que PFI2 não se limita a apontar aspectos a serem transformados, mas se mostra capaz de recriar uma proposta de ensino, o que nos revela o desenvolvimento de capacidades docentes em relação à autonomia e à criatividade do professor, colocando-o no papel de ator e não meramente executor de tarefas.

A concepção sobre o trabalho do professor com foco na concepção de linguagem e o objetivo do ensino de Língua Portuguesa está diretamente atrelada aos conhecimentos teóricos. Em cinco das dez aulas observadas, PFI1 fundamenta os encaminhamentos pedagógicos a partir da concepção de linguagem, como nos trechos a seguir (Excerto 3):

Excerto 3 - Concepção de linguagem de PFI1.

O objetivo de ensino da língua materna baseado no conteúdo e modelo de sua exposição pode ser considerado para conhecimento da norma padrão da lingua portuguesa, dado que é para o conhecimento do sistema linguístico. A linguagem pode ser concebida como expressão do pensamento, pois o conhecimento detido pela professora é transmitido por ela para os alunos de modo estanque demonstrando a concepção de língua como regras e códigos a serem adquiridos para uma construção mental eficiente do que se deseja falar (p. 22, grifos nossos).

A linguagem pode ser concebida como expressão do pensamento ao conceituar os modos como são categorizados as abstraç̃̃es realizadas na fala do denotativo para o conotativo para conhecimento sistemático da língua (p. 25 , grifos nossos). 
Em duas aulas geminadas, PFI1 aponta a concepção de linguagem como instrumento de comunicação justificando, para isso, que:

esta abordagem desconsidera o processo de produção em que a língua se realiza ao considerar apenas código e sua transmissão e decodificação. Na aula, os novos conceitos adquiridos facilitariam a decodificação futura dos termos apreendidos" (Aula 3, p. 24, grifos nossos).

A PFI2, embora confunda os conceitos das concepções de linguagem, atesta um ensino pautado na transmissão e decodificação, como podemos constatar neste excerto: "o conhecimento era uma mera transmissão de saber, sendo nenhum conhecimento prévio do aluno adquirido para obter relação com o conteúdo[...]" (Aulas 6 a 10, p. 50).

Nas aulas observadas, de modo geral, há a recorrência de "aula tradicional". Das dez aulas do diário, PFI2 faz menção a três descrições, definindo-as pela "organização da aula, e pelos conceitos e regras gramaticais estabelecidas no quadro, pelos exercícios apresentados e pelo andamento da aula". A PFI1 parece corroborar com a PFI2, ao afirmar que:

A professora apresenta metodologia marcada pela exposição oral e não utilização de material de apoio, as aulas são caracterizadas pelo modelo tradicional de ensino, alunos passivos sentados paralelamente, professora a frente da sala em nível acima do palco para melhor visualização e destaque (Aula 8, p. 29).

Isso nos indica que as PFI buscam respaldo teórico para reconhecer e refletir sobre a situação de ensino observada, atrelando à identidade do professor as opções políticas assumidas (ZANINI, 1999): os conteúdos selecionados para o ensino, o enfoque que se dá a esse conteúdo, as estratégias utilizadas, a escolha da bibliografia e o sistema da avaliação. Observamos que esses conceitos se voltam para a dinâmica de sala de aula (aula expositiva + carteiras enfileiradas + monólogo docente = alunos ouvintes e responsáveis pela execução das atividades propostas), o que nos leva a aproximar tais percepções aos saberes metodológicos e também aos saberes culturais. Metodológicos porque correspondem a uma forma de organização da didática da sala de aula e culturais porque quando se pensa em "aula" é justamente a equação supracitada a que mais a define, o que pode ser evidenciado no discurso de PFI2: 
V. 8 (3)

$204-229$

out-dez

2018

Excerto 4 - Descrição de metodologia de PFI2.

Quanto à metodologia empregada, a aula caracterizou-se por definições, conceitos e interpretações realizadas oralmente pela professora, assim como um monólogo, aos alunos, couberam o papel de ouvir as explicações e quando necessários e/ou obtivessem dúvidas perguntassem para que a professoras sanasse. (p. 50)

A etapa de observação, em linhas gerais, é apontada como uma atividade que contribui para o preparo profissional, bem como para a próxima etapa, o que representamos pelas palavras da PFI2: "as observações nos propicia um pensar sobre como será nossas aulas na regência criando um certa expectativa e um certo medo de errar" (Conclusão, p. 64).

Nesta seção, abordamos e discutimos alguns dados registrados pelas PFI nas primeiras etapas do Estágio in loco, o que nos conduz às impressões das PFI como diagnósticos, permitindo-nos analisar como os saberes docentes são acionados nos processos reflexivos das licenciandas e como podem contribuir para uma formação reflexiva, consciente e autônoma. Na próxima seção, o olhar volta-se para a atuação das estagiárias em seu período de regência.

Os diários reflexivos sobre aulas ministradas: a própria atuação

No diário sobre a regência, as PFI do curso de Letras refletem sobre a própria práxis, analisando a preparação das aulas, a atuação na regência e o trabalho em parceria com o colega de Estágio e com os estudantes da rede básica de ensino. No tocante à visão do serprofessor no período de regência, alguns pontos foram destacados pelas PFI como positivos e outros como aspectos a serem transformados, conforme ilustra a Quadro 2. 
Quadro 2 - Aspectos valorizados e a serem melhorados.

\begin{tabular}{|c|c|c|}
\hline $\begin{array}{c}\text { ASPECTOS/ } \\
\text { PFI }\end{array}$ & $\begin{array}{c}\text { PROFESSORA EM } \\
\text { FORMAÇÃO INICIAL } 1\end{array}$ & $\begin{array}{c}\text { PROFESSORA EM } \\
\text { FORMAÇÃO INICIAL } 2\end{array}$ \\
\hline $\begin{array}{l}\text { Aspectos } \\
\text { valorizados }\end{array}$ & $\begin{array}{l}\text { - Concepção de língua } \\
\text { como língua científica } \\
\text { - Valorização de aspectos } \\
\text { estruturantes da língua } \\
\text { - Oportunidade de } \\
\text { melhorar a fala para } \\
\text { facilitar a compreensão } \\
\text { dos alunos }\end{array}$ & $\begin{array}{l}\text { - Formação para a sala } \\
\text { de aula } \\
\text { - Relações significativas } \\
\text { entre conteúdo e } \\
\text { realidade dos alunos } \\
\text { - Agir em sala de aula } \\
\text { possibilitando } \\
\text { entendimento dos } \\
\text { conteúdos } \\
\text { - Possibilidade de } \\
\text { crescimento e } \\
\text { amadurecimento com a } \\
\text { dificuldade de regência } \\
\text { em dupla }\end{array}$ \\
\hline $\begin{array}{c}\text { Aspectos a } \\
\text { serem } \\
\text { transformados }\end{array}$ & $\begin{array}{l}\text { - Oralidade objetiva e } \\
\text { direta } \\
\text { - Problemas com } \\
\text { aspectos didático- } \\
\text { pedagógicos } \\
\text { - Ausência de ambição na } \\
\text { própria formação e } \\
\text { posicionamento como } \\
\text { professora em sala de } \\
\text { aula } \\
\text { - Reconhecimento dos } \\
\text { alunos durante a regência } \\
\text { em detrimento da própria } \\
\text { valorização } \\
\text { - Reconhecimento do } \\
\text { próprio dever como } \\
\text { professora em formação e } \\
\text { futura profissional }\end{array}$ & $\begin{array}{l}\text { - Incoerência entre o } \\
\text { uso da linguagem e a } \\
\text { postura de professora } \\
\text { - Ansiedade para falar e } \\
\text { transpor o conhecimento } \\
\text { aos alunos, dificultando } \\
\text { sua aprendizagem } \\
\text { - Regência em dupla } \\
\text { com dificuldade de } \\
\text { retomada do que foi dito } \\
\text { pela colega } \\
\text { (apresentação de } \\
\text { trabalho) }\end{array}$ \\
\hline
\end{tabular}

Fonte: As autoras.

Assim, constatamos que as PFI, em relação aos aspectos valorizados, apoiam-se, de modo especial, nos saberes teóricos oriundos da formação docente. Para PFI1, "conceber a língua cientificamente e valorizar os aspectos estruturantes da língua" (Autoavaliação, p. 78) reflete o reconhecimento da língua como objeto científico. No enunciado de PFI, "estabelecer uma linguagem e relações significativas entre o conteúdo e a realidade dos alunos" (Autoavaliação, p. 145) implica em uma concepção de aprendizagem que transcenda o repasse de informações. Enfim, há um reconhecimento do Estágio como uma oportunidade para melhorar a 
v. 8 (3)

204-229

out-dez

2018

produção oral do professor em formação no sentido de contribuir para o processo de aprendizagem dos alunos e para se obter uma preparação a fim de atuar em sala de aula estabelecendo relações significativas entre conteúdo e realidade de sala de aula de modo a possibilitar um maior entendimento dos conteúdos pelos alunos, considerada uma oportunidade de crescimento e amadurecimento no desenvolvimento da regência em dupla.

Quanto aos pontos a serem transformados, as PFI referem-se à necessidade de se ter conhecimentos mais aprofundados sobre os aspectos didático-pedagógicos quanto ao trabalho em sala de aula em detrimento ao reforço de conteúdos específicos da disciplina. Além disso, destacam o reconhecimento da própria falta de posicionamento como professora em sala de aula e como futuras profissionais, mencionando a preocupação sobre a coerência entre o uso da linguagem e essa postura, além do fato de a ansiedade para se expressar perante os alunos poder ser um impedimento para a efetivação do processo de ensino e aprendizagem. Ademais, as professoras em formação ressaltam que a regência em dupla pode dificultar o trabalho em parceria pela retomada do discurso da colega de Estágio.

No tocante à avaliação do Estágio por meio de oficinas, obtivemos algumas percepções das PFI, conforme ilustra o Quadro 3.

Quadro 3 - Percepções sobre o Estágio por meio de oficinas

\begin{tabular}{|c|c|}
\hline $\begin{array}{c}\text { PROFESSORA EM FORMAÇÃO } \\
\text { INICIAL } 1\end{array}$ & $\begin{array}{l}\text { PROFESSORA EM FORMAÇÃO } \\
\text { INICIAL } 2\end{array}$ \\
\hline $\begin{array}{l}\text { O formato da regência em } \\
\text { oficinas permite o conhecimento } \\
\text { da aplicação na prática de muitas } \\
\text { metodologias estudadas, porém } \\
\text { que foge da realidade da sala de } \\
\text { aula. Os alunos que se } \\
\text { dispuserem a irem às oficinas são } \\
\text { os que realmente têm interesses } \\
\text { em aprenderem algo novo, logo a } \\
\text { colaboração deles durante as } \\
\text { aulas foi positiva, lembrando que } \\
\text { por esse motivo o número de } \\
\text { alunos foi bem reduzido ( } p \text {. 77) }\end{array}$ & $\begin{array}{l}\text { Apesar de um grupo pequeno de } \\
\text { alunados devido as aulas serem } \\
\text { no contraturno, a maioria dos } \\
\text { alunados se interessou pela } \\
\text { atividade e questionamentos } \\
\text { estabelecidos, contudo como } \\
\text { professores, estabelecemos } \\
\text { linguagens formal e informal, } \\
\text { postura e conduta de professores } \\
\text { mediadores, aquele que partilha } \\
\text { e liberta os alunos da amarra da } \\
\text { ideologia de serem seres que } \\
\text { somente estão aprendendo e não } \\
\text { ensinam, portanto não } \\
\text { estabelecendo uma posição de } \\
\text { autoritarismos em sala de aula, } \\
\text { mas sim de autoria. (Aula 3, p. } \\
\text { 141) }\end{array}$ \\
\hline
\end{tabular}

Fonte: As autoras. 
No discurso de PFI1, encontramos uma ressalva quanto à finalidade da oficina para alunos do Ensino Médio: "Mas vale acrescentar que [...] o objetivo final é de atividades do vestibular, o que restringe a percepção da real compreensão dos alunos sobre conteúdo" (Aula 3, p. 76). Diante da preocupação quanto à função das oficinas desenvolvidas, julgamos que PFI1 apresenta uma reflexividade sóciocrítica e emancipatória ao questionar o porquê de se ensinar o que se ensinou nas oficinas de Estágio.

No que diz respeito à reconstrução das próprias aulas, PFI1 ressalta a necessidade de: (a) melhor preparação das acadêmicas acerca do conteúdo, para que, ao adequar a linguagem, possam facilitar a compreensão dos alunos; (b) planejamento do tempo, pois algumas atividades tiveram que ser suprimidas ou solicitadas como tarefa; e (c) aprofundamento de alguns conteúdos, para adequá-los ao nível exigido nos vestibulares. Com isso, PFI1 evidencia uma compreensão explícita sobre os objetivos que orientam suas ações nas oficinas, demonstrando o processo reflexivo esperado para o exercício profissional docente, uma vez que revisita sua própria prática levantando problemas e possíveis soluções, além de examinar criticamente suas ações, transcendendo, assim, ao conhecimento meramente técnico.

No discurso de PFI2, constatamos uma autoavaliação positiva quanto à atuação em sala de aula, sem deixar de apontar, todavia, algumas atividades que poderiam ser repensadas e abordadas de forma diferenciada. Suas reflexões referem-se à organização da aula, de atividades e ao controle temporal das ações desenvolvidas, conhecimentos adquiridos com a interação e com a prática diária da profissão. Esses dados permitem-nos entender a importância do Estágio na formação docente inicial e perceber como os diários enquanto instrumentos podem contribuir para uma formação menos técnica. Afinal, recorrendo às palavras de PFI2 "o estágio é uma disciplina que auxilia no crescimento e amadurecimento na formação e construção da identidade do docente" (Conclusão do relatório final, p. 146).

Quanto aos questionamentos norteadores deste estudo, as reflexões sobre as aulas observadas e implementadas pelas PFI nos permitiram a construção de um quadro-síntese, conforme Quadro 4. 
V. 8 (3)

204-229

out-dez 2018

Quadro 4 - Regularidades identificadas nos diários reflexivos

\begin{tabular}{|c|l|}
\hline SABERES & \multicolumn{1}{|c|}{ REGULARIDADES ENCONTRADAS NOS } \\
DIÁRIOS
\end{tabular}

Fonte: As autoras.

Após identificar os saberes mobilizados nos diários das PFI, foi possível reconhecer as possíveis correlações entre tais saberes, de modo que podem ser divididos em dois grupos; um que envolve os saberes formativos, referentes às práticas formativas nesse processo de formação docente, e o segundo que contempla os saberes sócio-culturais. A nosso ver, ambos os saberes podem ser considerados reflexivos, uma vez que integram a articulação entre os saberes a ensinar e para ensinar como aspectos fundamentais tanto à formação docente quanto ao trabalho docente, apontados no Esquema 1. 
Esquema 1 - Correlações entre os saberes identificados nos diários.

\section{SABERES A ENSINAR E PARA ENSINAR}

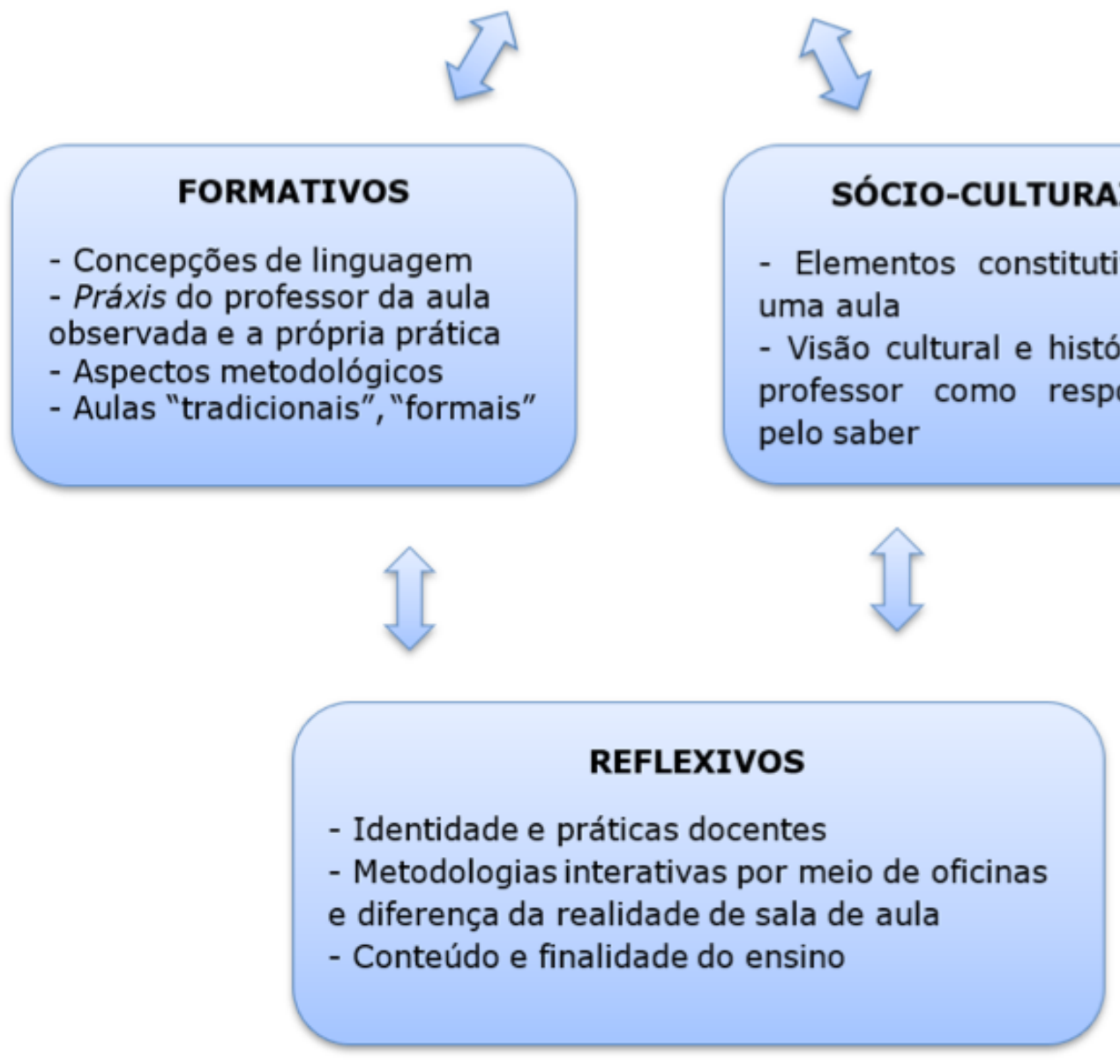

\section{SÓCIO-CULTURAIS}

- Elementos constitutivos de uma aula

- Visão cultural e histórica do professor como responsável pelo saber

Fonte: As autoras.

Notamos que os saberes oriundos da formação acadêmica são mobilizados ao se (re)pensar e questionar a prática observada, sua própria ação docente. Além disso, os procedimentos institucionais aos quais as PFI são submetidas no Estágio Supervisionado, no caso as Oficinas, conforme já mencionado neste texto, apesar de oferecerem liberdade de planejamento, não condizem com a realidade de sala de aula. No entanto, é possível perceber as contribuições do Estágio Supervisionado na formação dos professores de língua portuguesa, uma vez que diferentes saberes necessários a essa formação são articulados pelo uso de instrumentos como o diário reflexivo. Enfim, defendemos que, além de fichas técnicas pensadas para a observação de aulas e o período de regência, sejam utilizados outros recursos, como o diário reflexivo, por exemplo, que possam contribuir para um desenvolvimento mais preciso e seguro do professor no que diz respeito a uma compreensão mais ampliada do trabalho docente e do seu processo de formação. 
v. 8 (3)

204-229

out-dez

2018

\section{Considerações finais}

A descrição e análise de ações docentes e discentes nos possibilitaram problematizar não somentea prática pedagógica, mas a prática profissional do professor a fim de compreender o contexto educacional em que sua situação se insere, bem como pensar a necessidade de superação de obstáculos no processo de ensino e aprendizagem e no processo de formação, de modo consciente e engajado. As atividades desenvolvidas pelas PFI permitiram-lhes (re)ver, (re)construir e (res)significar concepções de linguagem, de ensino e de aprendizagem de línguas a partir de experiências vividas por profissionais da área na atividade docente. Os questionamentos levantados neste estudo possibilitam-nos reconfigurar e ressignificar nossas práticas formativas nos cursos de licenciatura.

Notocanteaoprimeiroquestionamentoapresentadonaintrodução deste texto, referente ao saberes docentes mobilizados e articulados nos diários produzidos pelos professores em formação participantes de nossa pesquisa, os dados nos propiciaram a identificação de correlações entre saberes vinculados às necessidades não somente de aprendizagem como também de formação dos nossos professores em desenvolvimento.

Quanto ao segundo questionamento sobre as possíveis contribuições do Estágio Supervisionado para a reflexão do trabalho docente e seus elementos constitutivos na formação inicial de professores de línguas, este trabalho também nos viabilizou a oportunidade de repensar e ressignificar nossas práticas formativas no sentido de prover oportunidades mais efetivas para o desenvolvimento dos nossos professores de amanhã.

Assim, defendemos que os processos reflexivos ocorram na formação docente por meio de diferentes instrumentos a fim de que possam contribuir para que os futuros professores possam entender tanto os elementos constitutivos da práxis docente na área de ensino de línguas quanto às dimensões sociais, políticas, históricas e culturais que envolvem essa situação de trabalho de modo mais ampliado. Reconhecemos também a necessidade de avançarmos em outros estudos e pesquisas para que, enquanto professores formadores e pesquisadores, possamos contribuir mais ampla e fortemente à consolidação do atendimento às necessidades de aprendizagem e formação profissional. Com isso, esperamos que outros estudos sejam desenvolvidos no sentido de darmos continuidade a esse debate social fundamental à formação inicial docente dos professores de línguas. 


\section{Referências}

ARRUDA, N. I. L.; GIMENEZ, T. O paradigma reflexivo e as diversas interpretações dos formadores de professores de inglês. Signum: Estud. Ling., Londrina, n.7/2, p.29-41, dez, 2004.

BAKHTIN, M. Estética da criação verbal. Introdução e tradução do russo Paulo Bezerra; prefácio à edição francesa Tzvetan Todorov. 4.ed. São Paulo: Martins Fontes, 2003. (Coleção Biblioteca Universal).

BOTA, C. et al. Intelligibilité de l'action de l'agir au servisse la La formation et du développement. In: BOTA, C.; CIFALI, M.; DURAND, M. (Orgs.) Recherche, Intervention, Formation, Travail: débats et perspectives dans le champ de la formation d'aultes, Cahiers des sciences de l'éducation, n.110. Genève: Université de Genève, 2006, p. 81-125.

BRONCKART, J-P. Du statut et des conditions de l'interprétation de l'activité humaine. In: CANELAS-TREVISI, S. (Org.). Langage, objets enseignés et travail enseignant, Grenoble: Ellug. 2009a, p.19-32.

BRONCKART, J-P.. Atividade de Linguagem, textos e discursos: por um interacionismo sócio-discursivo. Tradução: Anna Rachel Machado. São Paulo: Educ, 1999/2009b.

DIAS, S. M. A. O trabalho de professores de língua inglesa representado em diários reflexivos. In: REICHMANN, C. (Org.) Diários reflexivos de professores de línguas: ensinar, escrever, refazer(-se). Campinas, SP: Pontes Editores, 2013.

FACCI, M. G. D. Valorização ou esvaziamento do trabalho do professor?: um estudo crítico-comparativo da teoria do professor reflexivo, do construtivismo e da psicologia vigotskiana. Campinas, SP: Autores Associados, 2004. (Coleção formação de professores)

FREITAS, A. C. de M.; MEDRADO, B. P. Identidades, saberes e formação: respostas de um diário reflexivo. In: REICHMANN, C. (Org.) Diários reflexivos de professores de línguas: ensinar, escrever, refazer $(-\mathrm{se})$. Campinas, SP: Pontes Editores, 2013.

GERALDI, J. W. A aula como acontecimento. In: A aula como

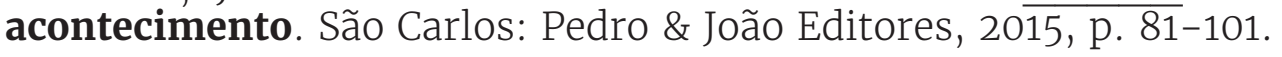

GIMENEZ, T. N. Learners becoming teachers: an exploratory study of beliefs held by prospective and practising EFL teachers in Brazil. 1994. Tese (Doutorado em Linguística Aplicada) - Lancaster University, 1994.

GIMENEZ, T. N.. O ensino de línguas estrangeiras na perspectiva do professor. Semina: Cl.Soc./Hum., Londrina, V.16, n.3, set. 1995.

GIMENEZ, T. N.. Reflective teaching and teacher education: contributions from teacher thinking. Linguagem e Ensino, v.2, n.2, p.129-143, 1999.

HOFSTETTER R.; SCHNEUWLY B. Savoirs en (trans)formation. Au cœur des professions de l'enseignement et de la formation. In: Hofstetter R. et Schneuwly B. Savoirs en (trans)formations des savoirs dans les formations aux professions enseignantes. Bruxelles: De Boeck, 2009, p. 6-22. 
V. 8 (3)

$204-229$

out-dez 2018

LIBÂNEO, J. C. Reflexibividade e formação de professores: outra oscilação do pensamento pedagógico brasileiro?. In: PIMENTA, S. G.; GHEDIN, E. (orgs.). Professor reflexivo no Brasil: gênese e crítica de um conceito. 7 ed. São Paulo: Cortez, 2012, p. 63-93.

LIBÂNEO, J. C. Formação de Professores e Didática para Desenvolvimento Humano. Educação e Realidade. Porto Alegre. v. 40, n. 2, p. $629-650$, abr/jun. 2015. Disponível em: <http://www.seer.ufrgs.br/index.php/ educacaoerealidade/article/view/46132/33422>. Acesso em: 22 abr. 2015.

LIBERALI, F. C. O diário como ferramenta para a reflexão crítica. 1999. Tese (Doutorado)-Pontifícia Universidade Católica de São Paulo, São Paulo, 1999.

PEREZ, M. Escrevendo e construindo-se professora: reflexões sobre o trabalho docente em um diário dialogado na formação inicial. In: REICHMANN, C. (Org.) Diários reflexivos de professores de línguas: ensinar, escrever, refazer(-se). Campinas, SP: Pontes Editores, 2013.

PIMENTA, S. G. Formação de professores: saberes da docência e identidade do professor. In: FAZENDA, Ivani C. A. (org.). Didática e Interdisciplinaridade. Campinas, SP: Papirus, 1998. p. 161-178. (Coleção Práxis)

PIMENTA, S. G. Professor reflexivo: construindo uma crítica. In: PIMENTA, S. G.; GHEDIN, E. (orgs.). Professor reflexivo no Brasil: gênese e crítica de um conceito. 4. ed. São Paulo: Cortez, 2006, p. 17-52.

PIMENTA, S. G. Formação de professores: identidade e saberes da docência. In: PIMENTA, Selma Garrido (org.) Saberes pedagógicos e atividade docente. 8. ed. São Paulo: Cortez, 2012.

PIMENTA, S. G.; LIMA, M. S. L. Estágio e Docência. 7. ed. São Paulo: Cortez, 2012. (Coleção docência em formação - Série saberes pedagógicos).

REICHMANN, C. L. Professores-em-construção: reflexões sobre reposicionamento identitário em um diário dialogado. Revista Leitura: Maceió, No. 39, p. 223-240, junho/2007.

REICHMANN, C. L.. (Org.) Diários reflexivos de professores de línguas: ensinar, escrever, refazer(-se). Campinas, SP: Pontes Editores, 2013.

SCHÖN, D. The reflective practitioner: how professionals think in action. New York: Basic Books, 1983.

SCHÖN, D. Educating the reflective practitioner: toward a new design for teaching and learning in the professions. San Francisco: Jossey-Bass, 1987.

SCHÖN, D. Coaching reflective teaching. In: GRIMMET, P.P.; ERICKSON, G. L. (Eds.) Reflection in teacher education. New York: Teachers College Press, 1988 .

STUTZ, L. Sequências didáticas, socialização de diários e autoconfrontação: instrumentos para a formação inicial de professores de inglês. 2012. 458f. Tese (Doutorado em Estudos da Linguagem) - Universidade Estadual de Londrina, 2012. 
TOGNATO, M. I. R. Educação a distância na formação continuada do professor de inglês: o caso do curso e590 da open university. 2002. 174p. Dissertação (Mestrado em Letras - Estudos da Linguagem) - Universidade Estadual de Londrina - UEL, Londrina - PR.

ZANINI, M. Uma visão panorâmica da teoria e da prática do ensino de língua materna. Acta Scientiarum, Maringá, v. 1, n. 21, p. 79-88, 1999.

ZEICHNER, K. M. Research on teacher thinking and different views of reflective practice in teaching and teacher education. In: CARLGREN, I.; HANDAL, G.; VAAGE, S. Teachers' minds and actions: research on teachers' thinking and practice. UK: London, The Falmer Press, 1994, p.9-27.

ZEICHNER, K. M. Para além da divisão entre professor-pesquisador e pesquisador acadêmico. In: GERALDI, C. M. G.; FRIORENTINI, D.; PEREIRA, E. M. de A. (Orgs.) Cartografias do trabalho docente: professor(a)-pesquisador(a). Campinas, Mercado de Letras, ALB, 1998, p. 207-236.

ZEICHNER, K. M. Uma análise crítica sobre a "REFLEXÃO" como conceito estruturante na formação docente. Educ. Soc. Campinas, v. 29, n.103, p.535554, maio/ago. 2008. Disponível em: http://www.cedes.unicamp.br. Acesso em: 15 abr. 2010. 